\title{
Strength Development and Pore Structure Characterisation of Binary Alkali-activated Binder Based on Tungsten Mining Waste
}

\section{Naim Sedira and João Castro-Gomes}

Centre of Materials and Building Technologies (C-MADE/UBI), Department of Civil Engineering and Architecture, University of Beira Interior (UBI), 6201-001 Covilhã, Portugal

\section{Abstract}

The mineralogical properties of tungsten mining waste mud (TMWM) make its valorisation and re-usage as an alumino-silicate source material to produce an alkaliactivated binder without calcination is a challenge. Moreover, the dissolution of silicate and alumina species from TMWM is very slow. Despite the crystallinity of TMWM, this study demonstrates that its combination with other sources of alumino-silicate source waste materials - such as red clay brick waste (RCBW), ground granulated blast furnace slag (GGBFS) and electric arc furnace slag (EAFS) - improved the compressive strength and the pore structure of the alkali-activated matrix. The combined precursors

Corresponding Author:

Naim Sedira

sedira.naim@ubi.pt

Received: 20 March 2020

Accepted: 30 April 2020

Published: 13 April 2020

Publishing services provided by Knowledge E

(c) Naim Sedira and João Castro-Gomes. This article is distributed under the terms of the Creative Commons

Attribution License, which permits unrestricted use and redistribution provided that the original author and source are credited.

Selection and Peer-review under the responsibility of the RICON19 - REMINE International Conference Conference Committee.

\section{G OPEN ACCESS} (90 vt.\%TMWM+10 vt.\%RCBW, 90 vt.\%TMWM+10 vt.\%GGBFS, and 90 vt.\%TMWM+10 vt.\%EAFS) were activated using a combination of alkaline activator solutions (sodium silicate and sodium hydroxide) with the ratio of 1:3 (66.6 wt.\% sodium silicate combined with 33.33 wt.\% of $\mathrm{NaOH} 10 \mathrm{M})$. The results show that the compressive strength increased from $11.23 \mathrm{MPa}$ at 28 days to reach $24.98 \mathrm{MPa}$ when the TMWM was partially replaced by $10 \mathrm{vt} . \%$ RCBW. In addition, this study shows that the interconnected porosity decreased where the critical pore size was reduced from $21.28 \mu \mathrm{m}$ to $0.55 \mu \mathrm{m}$ for the tungsten mining waste-based alkali-activated binder and the binary alkali-activated binder based on TMWM and RCBW.

Keywords: Mining Waste, Alkali-activated, Microstructure, MIP, Metakaolin

\section{Introduction}

Alkali-activated materials are attracting a substantial volume of research interest as an alternative binder to replace Portland cement to reduce $\mathrm{CO}_{2}$ emissions and global warming. The valorisation and re-usage of some waste minerals to produce new cementitious materials using the alkaline activation process technology by blending the precursors (minerals waste) with the alkaline activator solutions are one of the solutions that allow the reduction of $\mathrm{CO}_{2}$ emissions by re-using such waste [1]. Panasqueira is an underground mine located in the centre of Portugal which uses mechanised roomand-pillar mining methods. According to the recent technical report on the mineral 
resources and reserves of the Panasqueira mine made in 2016 [2], Panasqueira had 159 employees in its underground mining and plant operations that processed 16200 tonnes of ore per annum and produced an excess of 540 tonnes of tungsten oxide $\left(\mathrm{WO}_{3}\right)$ just about $0,3 \%$ of excavated rock. The re-usage of tungsten mining waste mud has been investigated since the initial study carried out by Pacheco-Torgal et al [3], in which they prepared alkali-activated materials using tungsten mining waste mud (TMWM) as a precursor, mixed with minor quantities of calcium hydroxide $\mathrm{Ca}(\mathrm{OH})_{2}$, as powder, and sodium hydroxide and waterglass as alkaline activator solutions. The alkaline activation reactions is the dissolution of an alumino-silicate minerals by a highly alkaline solution prior to precipitation reactions that form a gel binder [4]. In the study, the tungsten mining waste mud was subject to a thermal treatment at $950{ }^{\circ} \mathrm{C}$ for $2 \mathrm{~h}$. The alkali-activated mixtures that were prepared contained TMWM and $10 \%$ of $\mathrm{Ca}(\mathrm{OH})_{2}$, as powder, and $\mathrm{NaOH}$ with a concentration of $20 \mathrm{M}$, as alkaline activator solution, and $\mathrm{H}_{2} \mathrm{O} / \mathrm{Na}_{2} \mathrm{O}$ molar ratio $=10,8$. The binder was mixed with limestone aggregates (aggregate/binder ratio $=1.5$ ). The alkali-activated concrete resulted from their study had a compressive strength of $\mathrm{Fc}_{(56)}=65.3 \mathrm{MPa}$ after 56 curing days. Recently, several studies have been carried out to decrease the $\mathrm{CO}_{2}$ emission and the consumption of energy during the calcination process of the TMWM by combining TMWM with other alumino-silicate rich materials due to the low reactivity of untreated (non-calcined) tungsten mining waste mud (TMWM) with the alkaline activator solutions. TMWM was blended with other mineral waste (aluminosilicate rich materials) such as glass powder [5], brick powder [6], electric arc furnace slag [7] and granulated ground blast furnace slag [8] to produce alkali-activated binders. This research aimed to optimise the alkaline activation of TMWM by replacing $10 \mathrm{vt} . \%$ of TMWM with other minerals waste and understand the influence of the precursors combination on the mechanical strength and pore structure of the binders formed.

\section{Experimental Procedures}

\subsection{Materials}

The raw materials used in this investigation consisted of four powders as precursors: TMWM, EAFS, GGBFS and RCBW. The activator solution was a mix of sodium hydroxide $(\mathrm{NaOH})(\mathrm{SH})$ and sodium silicate $\left(\mathrm{Na}_{2} \mathrm{SiO}_{3}\right)(\mathrm{SS})$. 


\subsubsection{Precursors}

The main precursor used was TMWM that derived in its powder form from the mining waste disposal dam at Panasqueira mine. After the collection of the TMWM from the disposal dam, TMWM was dried at $100{ }^{\circ} \mathrm{C}$ for 24 hours. Then, the dried mud was mechanically disaggregated using a crushing machine and, finally, the mud was sieved to obtain particles of sizes under $500 \mu \mathrm{m}$. Two types of slags were used in the current study: ground granulated blast furnace slag (GGBFS) and electric arc furnace slag (EAFS). The GGBFS was obtained from the cement plant Ain El Kebira located in the northeast of Algeria. Before mixing, the GGBFS was sieved to obtain size particles under $63 \mu \mathrm{m}$. EAFS was received from the national steel industry in Maia and Aldeia de Paio Pires, Seixal, Portugal. The EAFS was placed, as received, in the oven at $60^{\circ} \mathrm{C}$ for 24 hours to dry. Afterwards, it was grinded into fine particles in a crusher mill consuming $12 \mathrm{kWh}$ per ton of steel slag crushed. Then, it was further pulverized in a ball mill consuming respectively $12.5 \mathrm{kWh}$ and $37.5 \mathrm{kWh}$ per ton of coarser and finer particles of steel slag powder [9]. The EAFS was sieved to obtain size particles under $250 \mu \mathrm{m}$. The particle size distribution curves of milled TMWM, GGBFS and MK are shown in Fig. 1. The powder particle size distribution was determined using laser diffraction (CILAS 1190). The average particle size diameter $\left(D_{50}\right)$ of TMWM, EAFS, GGBFS and RCBW were $145.83 \mu \mathrm{m}, 49.65 \mu \mathrm{m}, 10.91$ $\mu \mathrm{m}$ and $85.72 \mu \mathrm{m}$, respectively. The main chemical compositions of the four powders are given in Table 1. The chemical composition of the precursors was determined using a Hitachi S-4800 microscope instrument through the EDS (Energy Dispersive X-ray) analysis. The TMWM and RCBW contain high levels of $\mathrm{SiO}_{2}$ and $\mathrm{Al}_{2} \mathrm{O}_{3}$, while EAFS and GGBFS contain high levels of $\mathrm{CaO}$ which are essential for the alkali-activation, together with moderate amounts of Mg in TMWM, EAFS and GGBFS.

\subsubsection{Activator solutions}

The alkaline solution used was a mixture of an aqueous solution of sodium hydroxide (10 M) and sodium silicate. Sodium hydroxide solution was prepared by dissolving sodium hydroxide pellets ( $98.6 \%$ purity supplied by DOS SANTOS, LDA Portugal) in deionised water and allowed to cool before use. Sodium silicate (ref. D40), supplied by Solvay SA, Póvoa de Santa Iria, Portugal, had a modulus of silicate $\left(\mathrm{SiO}_{2} / \mathrm{Na}_{2} \mathrm{O}\right)=3.23(8.60 \%$ by weight $\mathrm{Na} 2 \mathrm{O}, 27.79 \%$ by weight $\mathrm{SiO}_{2}, 63.19 \%$ by weight $\mathrm{H}_{2} \mathrm{O}$, and 0.4 weight $\mathrm{Al}_{2} \mathrm{O}_{3}$ ). 


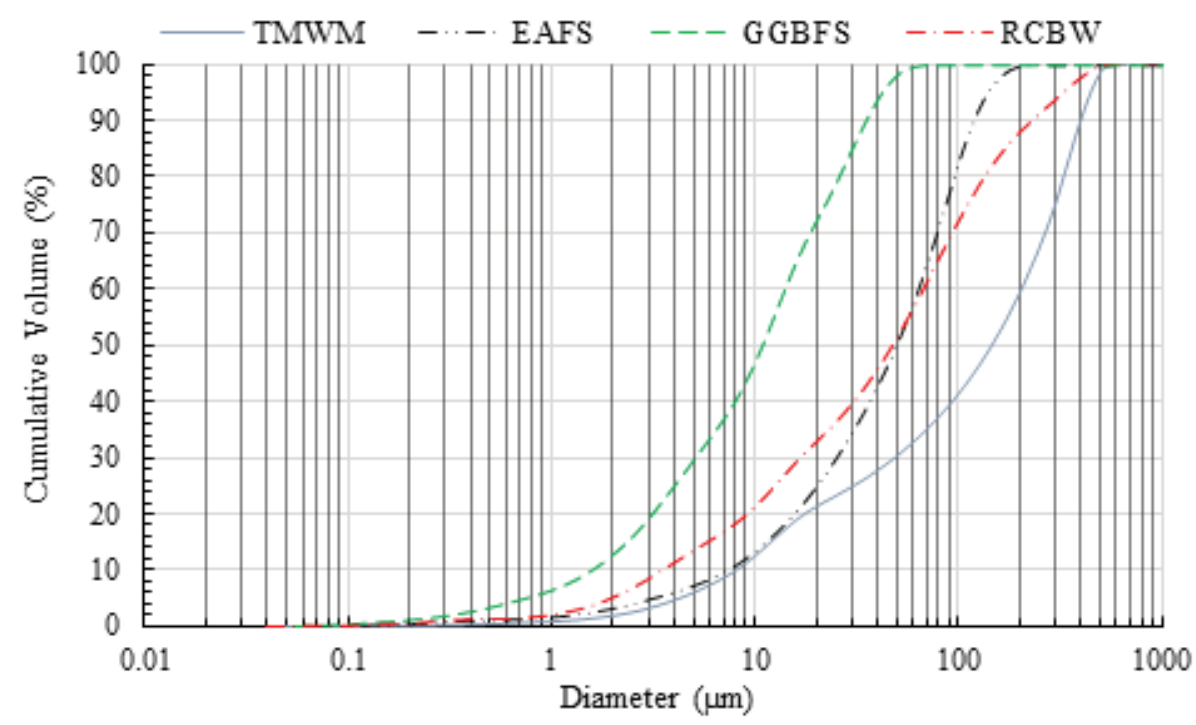

Figure 1: Particle size distribution of the four precursors.

TABLE 1: Chemical composition of the precursors (wt.\%).

Component
$\mathrm{Al}_{2} \mathrm{O}_{3}$
$\mathrm{SiO}_{2}$
$\mathrm{TiO}_{2}$
$\mathrm{SO}_{3}$
$\mathrm{~K}_{2} \mathrm{O}$
$\mathrm{CaO}$
$\mathrm{Fe}_{2} \mathrm{O}_{3}$
$\mathrm{MgO}$
$\mathrm{Na}_{2} \mathrm{O}$
$\mathrm{MnO}^{\mathrm{ZnO}}$
$\mathrm{Cr}^{\mathrm{P}} \mathrm{O}_{3}$

\begin{tabular}{|c|c|}
\hline TMWM \\
\hline 17.05 \\
\hline 46.67 \\
\hline 0.6 \\
7.9 \\
4.9 \\
0.69 \\
15.47 \\
4.83 \\
0.8 \\
- \\
\hline
\end{tabular}

\begin{tabular}{|c|}
\hline EAFS \\
\hline 10.08 \\
\hline 15 \\
\hline 0.82 \\
\hline 0.19 \\
\hline- \\
\hline 33.29 \\
\hline 30.48 \\
\hline 4.54 \\
\hline 0.13 \\
\hline 3.13 \\
\hline- \\
\hline 2.1 \\
\hline
\end{tabular}

\begin{tabular}{|c|}
\hline GGBFS \\
\hline 7.79 \\
\hline 34.09 \\
0.37 \\
1.27 \\
\hline 0.51 \\
\hline 48.71 \\
\hline 0.4 \\
\hline 5.09 \\
\hline 0.54 \\
\hline 0.23 \\
\hline
\end{tabular}

\begin{tabular}{|c|}
\hline RCBW \\
\hline 25.15 \\
\hline 59.58 \\
\hline 1.03 \\
\hline 0.38 \\
\hline 2.94 \\
\hline 0.82 \\
\hline 8.03 \\
1.47 \\
\hline 0.51 \\
- \\
\hline
\end{tabular}

\subsection{Samples preparation and analysis}

In this investigation, four mixtures were prepared. The first mixture was made with 100 vt. \% TMW. However, the other mixtures were a blend of 90 vt. \% of TMW with 10 vt.\% of other minerals waste (EAFS, GGBFS and RCBW). The precursors were mixed with the alkaline activator solutions in proportional weights. The $100 \mathrm{wt} . \% \mathrm{TMW}$ and the combination of precursors (90 vt. \% TMWM+10 wt.\% EAFS) and (90 vt. \% TMWM+10 vt.\% 
GGBFS) was mixed with the activator solution with the ratio $P / A=3$, and, the precursor (90 vt. \% TMWM+10 vt.\% RCBW) with the ratio $P / A=2.5$. The change of the P/A ratio in the different mixtures was to ensure the average workability of the pastes. The use of $P / A=3$ for the precursor ( 90 vt. \% TMWM+10 vt.\% RCBW) resulted in a stiff paste due to the presence of RCBW. Then, the ratio P/A ratio was decreased to a value of 2.5. Before preparing the mixtures, the activators were stirred together for 5 minutes using Magnetic stirrers "agimatic and selecta". The activator solution was added to the precursors and mixed by hand to get different alkaline activated mixtures. After that, the mixtures were placed in moulds by gravity. Then, the moulds were hand vibrated for two minutes. After mixing and moulding, the moulds were cured in an oven at $60{ }^{\circ} \mathrm{C}$ for $24 \mathrm{~h}$. After the experiment, the samples were removed from the oven and cooled at laboratory temperature. At 28 days of the reaction, the pastes were prepared for different analyses. The initial ratios [(Si/Al), $(\mathrm{Ca} / \mathrm{Si}),(\mathrm{K} / \mathrm{Al})$, and $(\mathrm{Na} / \mathrm{Si})]$ of the mixtures are given in Table 2.

TABLE 2: Mix proportions of raw materials, solutions and the element ratios of the mixtures.

\begin{tabular}{|c|c|c|c|c|c|c|c|c|c|c|c|}
\hline \multirow[t]{2}{*}{ Binders } & \multicolumn{4}{|c|}{ Precursors (wt. \%) } & \multicolumn{2}{|c|}{ Activator solutions } & \multirow{2}{*}{$\begin{array}{l}\mathrm{P} / \mathrm{A} \\
\text { ratios }\end{array}$} & \multicolumn{4}{|c|}{ Element ratios } \\
\hline & TMWM & EAFS & GGBFS & RCBW & SS (wt.\%) & SH (wt.\%) & & Si/Al & $\mathrm{Ca} / \mathrm{Si}$ & $\mathrm{K} / \mathrm{Al}$ & $\mathrm{Na} / \mathrm{Si}$ \\
\hline 100TMW & 100 & - & - & - & 66.67 & 33.33 & 3 & 2.209 & 0.018 & 0.223 & 0.175 \\
\hline 90TMW+10EAFS & 90 & 10 & - & - & 66.67 & 33.33 & 3 & 2.435 & 0.118 & 0.216 & 0.270 \\
\hline 90TMW+10GGBFS & 90 & - & 10 & - & 66.67 & 33.33 & 3 & 2.164 & 0.115 & 0.217 & 0.188 \\
\hline 90TMW+10RCBW & 90 & - & - & 10 & 66.67 & 33.33 & 2.5 & 2.383 & 0.016 & 0.213 & 0.213 \\
\hline
\end{tabular}

- The compressive strength values of synthesised alkali-activated binders were measured using a $3000 \mathrm{kN}$ electro-hydraulic mechanical testing machine "ADR Touch 3000 BS EN Compression Machine with Digital Readout and Self Centring Platens", as specified in European standard EN 196-1 with a loading rate of 0.05 $\mathrm{kN} / \mathrm{S}$. The results reported were the average of five replicates per each alkaliactivated binder sample and per age using $25 \mathrm{~mm}$ cubic size sample.

- Mercury intrusion porosimetry tests were conducted in a Microporometrics AutoPore IV9500V1.07 with maximum and minimum applied pressures of $413.7 \mathrm{MPa}$ and $3.63 \mathrm{kPa}$, corresponding to a minimum pore size of $5 \mathrm{~nm}$ and maximum pore size of $345 \mathrm{~mm}$. For MIP testing a sample weighing $1.5-2.5 \mathrm{~g}$ was taken from the original cube specimens at the curing age of 28 days. The samples left in a Glass Desiccator contain from Silica gel to ensure the removal of the moisture samples. 


\section{Results and Discussion}

\subsection{Compressive strength}

Fig. 2 and Table 3 show the 7, 14, and 28 days compressive strength values of tungsten mining waste-based alkali-activated binder, and the other binary alkali-activated binders based on tungsten mining waste samples. It is clear that the binary alkaliactivated samples have higher compressive strength than the sample made with $100 \%$ tungsten mining waste-based alkali-activated binder. The compressive strengths of all alkali-activated binders are increasing with the increase of the curing time, especially in the first 7 days in which the compressive strength of the samples 100TMW and 90TMW+10EAFS reach $7.73 \mathrm{MPa}$ and $14.66 \mathrm{MPa}$ respectively, with an increase ratio of $68.83 \%$ from the compressive strength results that reached $11.23 \mathrm{MPa}$ for 100TMW and 17.86 MPa for 90TMW+10EAFS at 28 days. However, the binary alkaliactivated binder samples (90TMW+10GGBFS and 90TMW+10RCBW), their compressive strengths increased significantly by $82.08 \%$ with the value $17.2 \mathrm{MPa}$ for the sample 90TMW+10GGBFS, and increased by $78.18 \%$ with the value $18.57 \mathrm{MPa}$ for the sample $90 T M W+10 R C B W$ in the first 7 days, in which the increasing ratios were calculated from the compressive strengths of the samples after 28 days. The compressive strengths of the alkali-activated binders keep slightly increasing between 7 and 28 curing days, to reach 11.23 MPa, 17.86 MPa, $22 \mathrm{MPa}$, and 24.98 MPa for the samples 100TMW, 90TMW+10EAFS, 90TMW+10GGBFS and 90TMW+10RCBW, respectively, as shown in Table 3. To investigate the positive role of the partial replacement of $10 \mathrm{vt}$. \% TMWM with amounts of $10 \mathrm{vt}$ \% of other mineral waste as a precursor (EAFS, GGBFS, RCBW) on the compressive strength development of the alkali-activated samples, a comparative study was conducted on the samples containing 100 vt.\% TMWM, as a precursor (100TMW sample) and the samples containing the binary precursors. The 28 days compressive strength of 100TMW sample gave a compressive strength of $11.23 \mathrm{MPa}$. This positive value increases when $10 \mathrm{vt} . \%$ of the precursor TMWM was partial replaced (10 vt.\%) of EAFS or GGBFS or RCBW in different mixtures to reach 17.28 MPa, $22 \mathrm{MPa}$ and 24.98 MPa for the samples 90TMW+10EAFS, 90TMW+10GGBFS and 90TMW+10RCBW which increased by $59.04 \%, 95.9 \%$ and $122.44 \%$, respectively, when compared to the $100 T M W$ sample. The lower compressive strength of the 100TMW sample is related to the lower reactivity of the precursor (TMWM) with the alkaline activator solutions. Besides that, only a small part of the precursor (TMWM) reacts with the activator solutions due to the crystalline mineralogical composition of the TMWM. However, the compressive strengths results were ameliorated when the TMWM was partially replaced by $10 \mathrm{vt} . \%$ 
of EAFS, GGBFS and RCBW due to their chemical composition and their mineralogical composition. It is noted that, RCBW reacts better with TMWM and the activator solutions than the alkali activation of TMWM with EAFS and GGBFS. However, GGBFS reacts better with the TMWM and the activator solutions than the alkali activation reaction of EAFS.

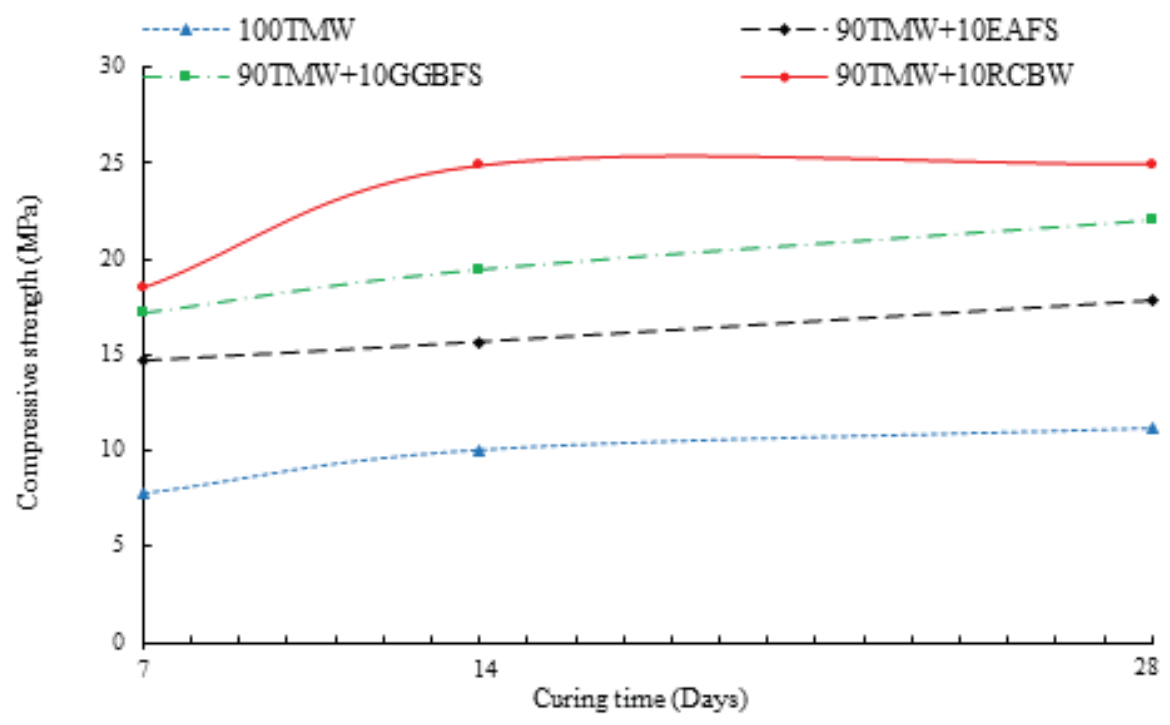

Figure 2: Compressive strength development of the AABs during curing time of 7, 14 and 28 days.

TABLE 3: Compressive strength of the alkali-activated binder.

\begin{tabular}{|c|c|c|c|c|}
\hline \multirow{2}{*}{$\begin{array}{l}\text { Curing time and } \\
\text { compressive strength } \\
\text { (CS) increase (\%) }\end{array}$} & \multicolumn{4}{|c|}{ Alkali-activated binders } \\
\hline & 100 TMW & 90TMW+10EAFS & 90TMW+10GGBFS & 90TMW+10RCBW \\
\hline CS at 7 days & 7.73 & 14.66 & 17.2 & 18.57 \\
\hline $\begin{array}{l}\% \text { of CS acquired } \\
\text { from 1st to 7th days }\end{array}$ & 68.83 & 68.83 & 82.08 & 78.18 \\
\hline CS at 14 days & 10.07 & 15.66 & 24.92 & 24.92 \\
\hline $\begin{array}{l}\% \text { of CS acquired } \\
\text { from } 7 \text { th to } 14 \text { th days }\end{array}$ & 20.84 & 20.84 & 5.60 & 10.18 \\
\hline CS at 28 days & 11.23 & 17.86 & 22 & 24.98 \\
\hline $\begin{array}{l}\% \text { of CS acquired from } \\
14 \text { th to } 28 \text { th days }\end{array}$ & 10.33 & 10.33 & 12.32 & 11.64 \\
\hline
\end{tabular}

\subsection{Mercury Intrusion Porosimetry}




\subsubsection{Total porosity and Pore size distribution}

In this study, four alkali-activated binder samples named (100TMW, 90TMW+10EAFS, 90TMW+10GGBFS and 90TMW+10RCBW) were tested by MIP. For each sample, 290 data were collected which used to obtain the Skeletal density, the total porosity and the average pore diameter, and the pore size distribution integral curve and the pore size distribution differential curves were also plotted in Fig.3.

The skeletal density of the alkali-activated binder changed when $10 \mathrm{vt} . \%$ of TMWM was partially replaced by other mineral waste, for the sample 100TMW the skeletal density is $3.44 \mathrm{~g} / \mathrm{cm}^{3}$. This value was increased in the sample that had $10 \mathrm{vt} . \%$ EAFS to reach $3.84 \mathrm{~g} / \mathrm{cm}^{3}$ and decreased for the samples 90TMW+10GGBFS and 90TMW+10RCBW with a skeletal density of $2.88 \mathrm{~g} / \mathrm{cm}^{3}$ and $2.71 \mathrm{~g} / \mathrm{cm}^{3}$, respectively. It was observed that the variation of the skeletal density depends on the density of the primary precursors were the EAFS is denser than the other precursors. Additionally, it was observed that the total porosity decreased for those samples in which $10 \mathrm{vt. \%}$ of TMWM was partially replaced by EAFS, GGBFS and RCBW. The results show that the total porosity of $100 \%$ tungsten mining waste-based alkali-activated contains $43.88 \%$. of total porosity. However, the total porosities were reduced to $37.63 \%, 25.41 \%$ and $27.28 \%$ for the samples 90TMW+10EAFS, 90TMW+10GGBFS and 90TMW+10RCBW, respectively.

The average pore diameters of all the alkali-activated samples varied over the range 0.04-0.26 $\mu \mathrm{m}$, a slight reduction in the average pore diameter from 0.26 $\mu \mathrm{m}$ for the 100TMW to $0.22 \mu \mathrm{m}$ and $0.18 \mu \mathrm{m}$ for the samples 90TMW+10EAFS and 90TMW+10GGBFS, respectively. In addition, a significant reduction in average pore diameter with value of $0.04 \mu \mathrm{m}$ for the sample 90TMW+10RCBW as the lowest result compared with the other samples. The $100 \mathrm{TMW}$ sample is more porous and present a higher average pore diameter than those with partial replacement of $10 \mathrm{vt} . \%$ TMWM were the sample 100TMW shows the highest average pore diameter however the 90TMW+10RCBW sample shows the lowest average pore diameter average pore diameter.

Fig.4 presents the different cumulative pore size distributions of all the samples, according to the International Union of Pure and Applied Chemistry (IUPAC) system [10]. Pores in the four alkali-activated binders can be classified into four categories: micropores $(\mathrm{d}<2 \mathrm{~nm})$, mesopores $(2 \mathrm{~nm}<\mathrm{d}<50 \mathrm{~nm})$, macropores $(50 \mathrm{~nm}<\mathrm{d}<10 \mathrm{~mm})$ and voids and microcracks ( $d>10 \mathrm{~mm}$ ). The micropores (ranges $\mathrm{d}>2 \mathrm{~nm}$ ) cannot be measured using the MIP technique because the data given are limited and there is a minimum pore diameter of $0.005 \mathrm{~mm}(5 \mathrm{~nm})$ that can be evaluated. However, it 
is possible to measure the mesopores, macropores and voids and microcracks [11]. The dominant range for the sample 100TMW was coarse pores with the size $(d>$ $10 \mathrm{~mm}$ ) consequence of air voids/microcracks in the paste with a value of $65.44 \%$, followed by the macropores $30.96 \%$ and mesopores $3.6 \%$. However, for the binary alkali-activated specimens the ranges of coarse pores $(\mathrm{d}>10 \mathrm{~mm})$ were diminished to $32.67 \%$ for the 90TMW+10EAFS sample, and $8.3 \%$ and $4.64 \%$ for the $90 T M W+10 G G B F S$ and 90TMW+10RCBW samples, respectively. On the other hand, the proportion of macropores and mesopores are increased for the binary alkali-activated binders. In the range of mesopores, the 100TMW specimen had the lowest percentage with only $3.66 \%$, while 90TMW10RCBW had the highest percentage of mesopores with $33.1 \%$. The partial replacement of TMWM with 10 vt.\% of EAFS, GGBFS and RCBW results in restricted pore size in the ranges of macropores and mesopores. It was seen that when the range of air voids/microcracks content in the sample increases, the compressive strength decreases. Moreover, the decrease in larger pores and the increase in macropores and mesopores proportions may be caused by the filling of the larger pores due to the formation of reaction products such as N-A-S-H, C-A-S-H and gels (N, M)-A-S-H in which M is Ca or $\mathrm{K}$, in the microstructure of the pastes to form a dense matrix, which affects positively not only the porosity but also the pore size distribution [12].

\subsubsection{Characterisation of pore size}

Another important measurement was obtained using MIP which is the critical pore diameter (or most probable diameter). The critical pore diameter is the inflection point on the volume intrusion versus pore diameter curve (or the maximum peak of the $\mathrm{dV} / \mathrm{dp}$ curve) as shown in Fig.3b and Table 4. Katz and Thompson [13] suggested that this point corresponds to the smallest pore size diameter of the subset of the largest pores which creates a connected path through the alkali-activated samples.

The critical pore diameter showed that the largest fraction of interconnected pores of tungsten mining waste-based alkali-activated binder sample prepared with 100 TMWM has a greater diameter than the binary alkali-activated binder samples. For the 100TMW sample, the critical pore diameter was $21.28 \mu \mathrm{m}$, while the critical pore diameter for binary alkali-activated samples (90TMW+10EAFS and 90TMW+10GGBFS) was $9.04 \mu \mathrm{m}$ and $5.71 \mu \mathrm{m}$. However, the critical pore diameter decreased significantly to reach 0.55 $\mu \mathrm{m}$ for of the $90 \% \mathrm{TMW}+10 \mathrm{RCBW}$ sample. The critical pore size diameter increased for the 100TMW alkali-activated sample because the poor development of the alkaline activation products due to the poor reactivity of TMWM particles, so the capillary pores 
are possibly formed by the spaces between unreacted TMWM particles. The fact that the binary alkali-activated binder samples have a lower critical pore size diameter means that more particles are reacting, and more reaction products are formed in the matrix.

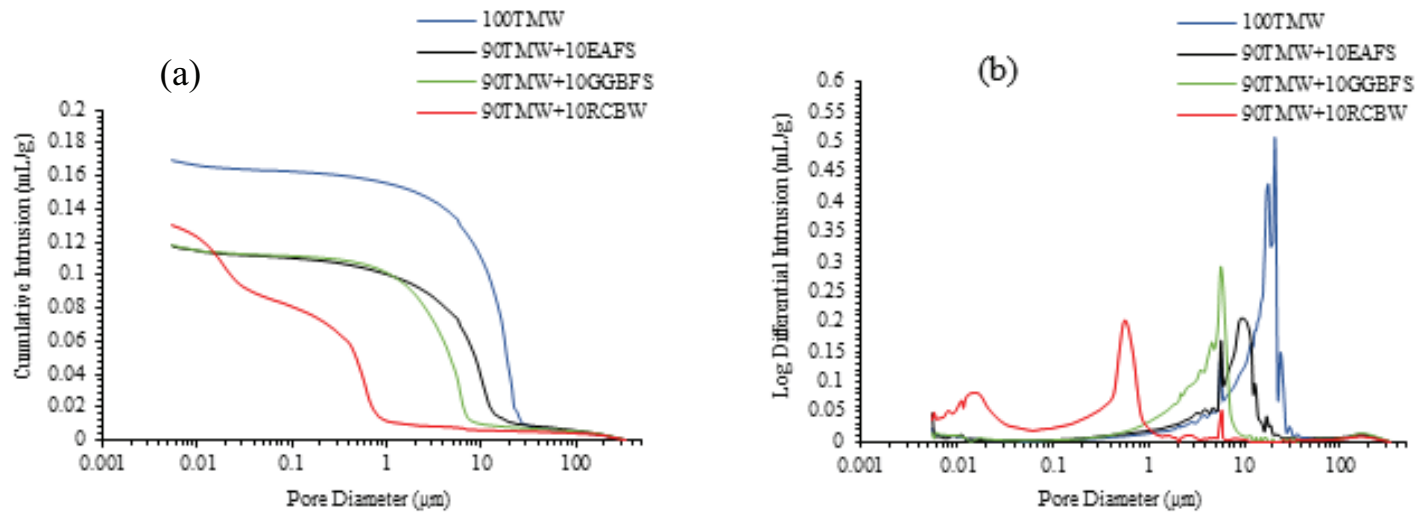

Figure 3: Cumulative pore size distribution (a) and differential pore size distribution (b) of the 100 TMW-AAB and the binary-AABs samples measured by MIP.

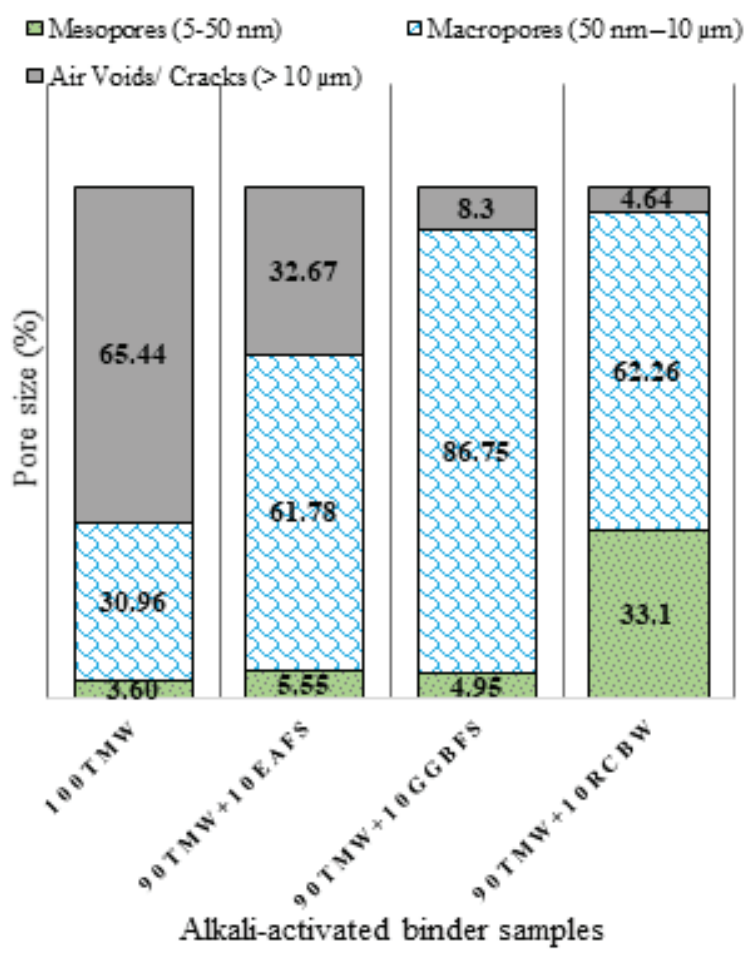

Figure 4: Pore volume distribution of the alkali-activated binders Pastes measured by MIP with IUPAC pore classification

\section{Conclusions}

The influence of the partial replacement of $10 \mathrm{vt} \%$ of TMWM by $10 \mathrm{vt} . \%$ of EAFS, GGBFS and RCBW on strength and pore structure of tungsten mining waste-based 
TABLE 4: Pore size proportions with IUPAC classifications for 100TMW-AAB and the binary-AABs.

\begin{tabular}{|c|c|c|c|c|c|}
\hline $\begin{array}{l}\text { Alkali-activate } \\
\text { ples }\end{array}$ & binder sam- & 100TMW & 90TMW+10EAFS & 90TMW+10GGBFS & 90TMW+10RCBW \\
\hline Skeletal dens & $y\left(\mathrm{~g} / \mathrm{cm}^{3}\right)$ & 3.44 & 3.84 & 2.88 & 2.71 \\
\hline Porosity (\%) & & 43.88 & 37.63 & 25.41 & 27.28 \\
\hline Average pore & diameter $(\mu \mathrm{m})$ & 0.26 & 0.22 & 0.18 & 0.04 \\
\hline $\begin{array}{l}\text { Most probabl } \\
\text { ter }(\mu \mathrm{m})\end{array}$ & (critical) diame- & 21.28 & 9.04 & 5.71 & 0.55 \\
\hline $\begin{array}{l}\text { Pore size } \\
\text { percentages }\end{array}$ & $\begin{array}{l}\text { Mesopores } \\
(5-50 \mathrm{~nm})\end{array}$ & 3.6 & 5.55 & 4.95 & 33.1 \\
\hline & $\begin{array}{l}\text { Macropores } \\
(50 \mathrm{~nm}-10 \\
\mu \mathrm{m})\end{array}$ & 30.96 & 61.78 & 86.75 & 62.26 \\
\hline & $\begin{array}{l}\text { Air Voids/ } \\
\text { Cracks (> } 10 \\
\mu \mathrm{m})\end{array}$ & 65.44 & 32.67 & 8.3 & 4.64 \\
\hline
\end{tabular}

alkali-activated binders are investigated in the current study. Based on the investigation, it is concluded that:

- Either way, the compressive strength increased when TMWM was partial replaced with $10 \mathrm{vt} . \%$ of other minerals waste. Moreover, higher compressive strength was obtained when TMWM was partial replaced with RCBW.

- The pore structure of the alkali-activated binders was improved when $10 \mathrm{vt} . \%$ of EAFS, GGBFS and RCBW partial replaced the TMWM where the total porosity was significantly reduced for the binary alkali-activated binders.Furthermore, the main difference between 100TMW alkali-activated binder and binary-alkaliactivated binders is that 100TMW alkali-activated binder pores are predominantly composed of coarse pores (voids/microcracks with diameter $(>10 \mu \mathrm{m})$ ), whereas binary alkali-activated binders pores contain higher proportion of macropores and mesopores.

- Blending of tungsten mining waste with other mineral waste (alumino-silicate rich powders) generate more reaction products. The reaction products improved the pore structure and formed dense binder structure which increase the compressive strength results

- The compressive strength of the alkali-activated binder depends to the pore structure, while the sample 100TMW has the higher proportion of coarse pore and 
the lower compressive strength results. However, the sample has lower proportion of coarse pores and higher mesopores reach higher compressive strength results.

\section{Acknowledgements}

This work was partially supported by the Doctoral Incentive Grant BID/ICI-FE/Santander Universidades-UBI/2019 financed by the Santander-Totta bank and the University of Beira Interior.

This work was also partially financed by Portuguese national funds through FCT Foundation for Science and Technology, IP, within the research unit C-MADE, Centre of Materials and Building Technologies (CIVE-Central Covilh a-4082), University of Beira Interior, Portugal.

\section{References}

[1] Sedira, N., et al. (2017). A review on mineral waste for chemical-activated binders: mineralogical and chemical characteristics. Min. Sci., vol. 24, pp. 29-58.

[2] Wheeler, A. (2016). "Report NI 43-101 Technical Report On The Mineral Resources And Reserves Of The Panasqueira Mine, Portugal," Almonty Industries, https://almonty.com/wp-content/uploads/2019/06/Panasqueira_43101_Tech_Rep_Dec16_SEDAR.pdf. Accessed 10 Nov. 2019.

[3] Pacheco-Torgal, F., Castro-Gomes, J. and Jalali, S. (2009). Tungsten mine waste geopolymeric binder: Preliminary hydration products investigations. Constr. Build. Mater., vol. 23, pp. 200-209.

[4] Davidovits, P. J. (2002). "30 Years of Successes and Failures in Geopolymer Applications. Market Trends and Potential Breakthroughs," Geopolymer 2002 Conference, October 28-29, Melbourne, Australia. pp. 1-16.

[5] Kastiukas G. and Zhou, X. (2017). Effects of waste glass on alkali-activated tungsten mining waste: composition and mechanical properties. Mater. Struct. Constr., vol. 50, issue 4, 2017.

[6] Sedira N. and Castro-Gomes, J. (2018). Study of an alkali-activated binder based on tungsten mining mud and brick powder waste. 8th Sci. Conf. Mater. Probl. Civ. Eng., vol. 06002, pp. 1-8.

[7] Sedira N. and Castro-Gomes, J. (2019). Effects of EAF-S on alkali-activation of tungsten mining waste: mechanical properties. REMINE - International Conference \& Brokerage Event (RICON17) - UBI, Covilha, Portugal, 2019, vol. 01003, pp. 1-6. 
[8] Sedira N. and Castro-Gomes, J. (2018). Strength and microstructure of tungsten mining waste-based hybrid alkaline material: effect of activators. Proceedings of the 12th fib International PhD Symposium in Civil Engineering, 2018, pp. 145-152.

[9] Humbert, P. S., Castro-Gomes, J. P. and Savastano, H. (2019). Clinker-free CO 2 cured steel slag based binder: Optimal conditions and potential applications. Constr. Build. Mater., vol. 210, pp. 413-421.

[10] IUPAC (1972). Manual of symbols and terminology, appendix 2, part 1, Colloid and Surface Chemistry. Pure Appl. Chem., vol. 31.

[11] Sedira N. and Castro-Gomes, J. (2020). Effect of activators on hybrid alkaline binder based on tungsten mining waste and ground granulated blast furnace slag. Constr. Build. Mater., vol. 232, p. 117176.

[12] Sedira, N., Castro-Gomes, J. and Magrinho, M. (2018). Red clay brick and tungsten mining waste-based alkali-activated binder: Microstructural and mechanical properties. Constr. Build. Mater., vol. 190, pp. 1034-1048.

[13] Katz A. J. and Thompson, A. H. (1987). Prediction of rock electrical conductivity from mercury injection measurements. J. Geophys. Res., vol. 92, pp. 599-607. 